\title{
The importance of maintaining normal perioperative physiological parameters in children during anaesthesia
}

\author{
Is'haq Al Aamri ${ }^{1}$, Gianluca Bertolizio ${ }^{1, *}$
}

${ }^{1}$ Department of Anesthesia, McGill University, Montreal Children's Hospital, Montreal, Canada

\section{*Correspondence}

gianluca.bertolizio@mcgill.ca

(Gianluca Bertolizio)

\begin{abstract}
Every year, millions of neonates, infants and young children need general anesthesia for a variety of procedures. As pediatric anesthesia remains at high risk of perioperative morbidity and mortality, attention has been directed towards the anesthesia training and the anesthetics safety. We are now reassured about the relatively safeness of the anesthetic drugs, but the safest intraoperative conduct has still to be determined. In the absence of clear evidence, it appears logical to prevent perturbations of the child "baseline", by avoiding preoperative distress, maintaining normal intraoperative parameters and preventing postoperative discomfort. Recently, ten "N" principles (no fear/awareness, normovolemia, normotension, normal heart rate, normoxemia, normocapnia, normonatremia, normoglycemia, normotermia and no pain/nausea/vomiting/emergence delirium) have been proposed as the base of a safer anesthesia care. The current paper aims to summarize the current evidence behind the "10-Ns" rational and to help guide anesthesiologists in their practice.
\end{abstract}

\section{Keywords}

Safetots; Pediatric anesthesia; Pediatric homeostasis

\section{Introduction}

Children undergoing general anesthesia have an increased risk for morbidity and mortality compared to adults [1], especially in the hands of occasional pediatric anesthetists [2]. Respiratory complications and cardiovascular instability are the most common perioperative severe critical events [3] and can be avoided by adequate training and exposure [1-3]. The focus of safety in pediatric anesthesia has now shifted from the quest for the safest anesthetic agent to the known and established risk: the conduct of anesthesia [1-4]. Along with providing extra training in pediatrics [5], an overarching framework for critical elements in clinical anesthesia, "10Ns", has been developed (http://www. safetots . org) [1] (Fig. 1). This paper reviews these elements to help everyday pediatric anesthesia practitioners.

\section{No fear, no awareness}

Preoperative anxiety and intraoperative awareness are well known but yet underestimated anesthesia related complications. Pre-operative anxiety affects $50 \%$ to $75 \%$ of the children undergoing surgery. Long lasting maladaptive behaviors such as nightmares, separation anxiety, eating problems and increased fear of doctors can persist in $19 \%$ of the children for 6 months and in $6 \%$ for one year postoperatively [6]. Several pharmacological $[7,8]$ and non-pharmacological $[8-$ 10] interventions have investigated to decrease children anx- iety, including virtual reality [11]. Age appropriate psychological and educational preparation, parenteral presence, and premedication have shown to be effective in reducing anxiety preoperatively $[6,7,9,12]$ (Table 1 ).

Intraoperative awareness is estimated to be as high as $1.2 \%$ in children, which is 6 times more frequent than in adults [13]. The real incidence is, however, unknown, as children may confound real and imaginary events, may perceive the recall experiences less distressful than adults, or may be unable to communicate their experience. To date, there are no data on awareness in patients $<3$ years of age [13]. Contrary to adults, long term consequences are also unclear [14].

Determining the adequate depth of anesthesia in children is not easy. In fact, row electroencephalography (EEG) analysis is a very good technique to monitor the depth of anesthesia, however, interpreting the EEG requires expertise [15]. On the contrary, the Bispectral index (BIS), a processed EEG widely used in adults, does not have a linear correlation with the concentrations of sevoflurane in children, varies with age (higher in younger children) and poorly predicts the level of consciousness in children less than 3 years old $[15,16]$. It is also affected by medications such as ketamine and nitrous oxide, commonly used in pediatric anesthesia [16]. Several alternatives are currently under investigation [17], but data in children are still limited. 


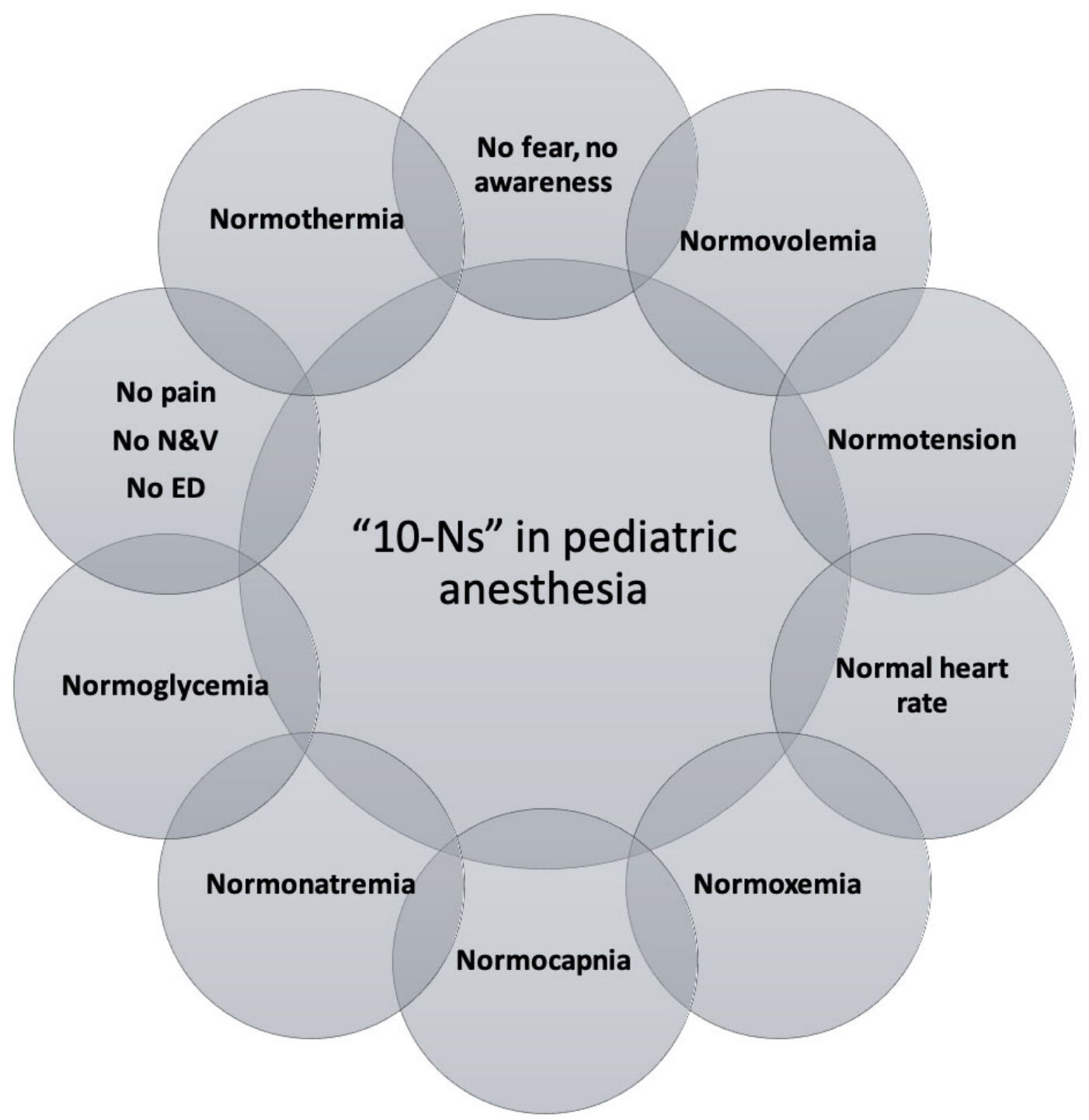

F I G U R E 1. 10-N concept of pediatric anesthesia. Adapted from www . saf etots . org .

TA B L E 1. Risk factors and proposed interventions and measure to reduce preoperative anxiety.

\begin{tabular}{|c|c|c|}
\hline Risk factors for preoperative anxiety & Non-pharmacological intervention & Pharmacological intervention \\
\hline $\begin{array}{l}\text { Age (1-5 years) } \\
\text { High baseline anxiety } \\
\text { Children with passive coping style } \\
\text { (ex. avoidance, violence) } \\
\text { Attention deficit hyperactivity } \\
\text { disorder (ADHD) } \\
\text { Previous medical and surgical encounters } \\
\text { Parental anxiety }\end{array}$ & $\begin{array}{l}\text { Parental presence during induction } \\
\text { Pre-operative preparation programs } \\
\text { Audiovisual (AV) interventions } \\
\text { (videos, multi-faceted programs, } \\
\text { interactive games, virtual reality music } \\
\text { and Internet programs) } \\
\text { Clowns or clown doctors } \\
\text { Quiet environment } \\
\text { Hypnosis } \\
\text { Parental acupuncture } \\
\text { Childlife specialists }\end{array}$ & $\begin{array}{l}\text { Benzodiazepines (Midazolam, Diazepam) } \\
\text { Ketamine } \\
\text { a2-adrenergic agonists } \\
\text { (Dexmedetomidine, Clonidine) } \\
\text { Opioid (morphine) } \\
\text { Chloral hydrate }\end{array}$ \\
\hline
\end{tabular}

\section{Normovolemia}

Perioperative fasting times should be as short as possible to prevent patient discomfort, dehydration, post-induction hypotension, ketoacidosis and a catabolic state [18, 19].

In children, guidelines recommend the administration of water or sugar-containing clear fluids up one hour before surgery [20]. However, fasting times are often exceeded in the clinical practice. Avoidance of prolonged fasting may be particular challenging in infants, who preferentially drink milk that must be administered no later than four to six hours before surgery [20].

According to the Association of the Scientific Medical Societies in Germany, fluid maintenance should employ balance isotonic solutions instead of Ringer Lactate or $0.9 \%$ saline [18]. In fact, Ringer Lactate is mildly hypotonic compared to plasma 
TA B L E 2. Prevention of post-operative nausea and vomiting.

\begin{tabular}{|c|c|}
\hline Risk Factors for POV \& PONV & Extra rescue medication if needed in PACU \\
\hline $\begin{array}{l}\text { Age } \geq 3 \text { years } \\
\text { History of POV/ PONV/motion sickness } \\
\text { Family history of POV/ PONV } \\
\text { Sex: Post-pubertal female } \\
\text { Surgery } \geq 30 \text { minutes } \\
\text { Volatile anesthetics } \\
\text { Anticholinesterases } \\
\text { Long-acting opioids } \\
\text { Strabismus surgery Adenotonsillectomy } \\
\text { Otoplasty }\end{array}$ & 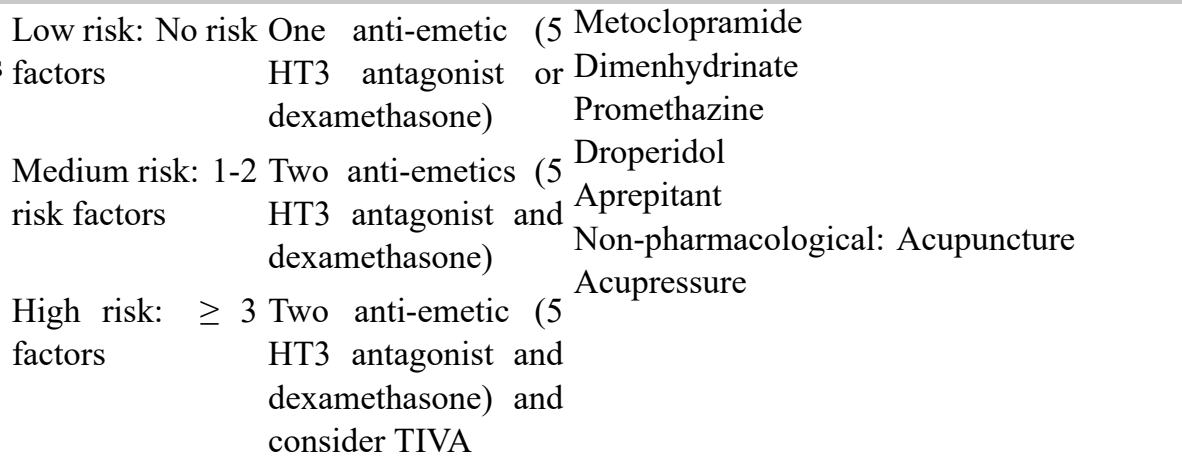 \\
\hline
\end{tabular}

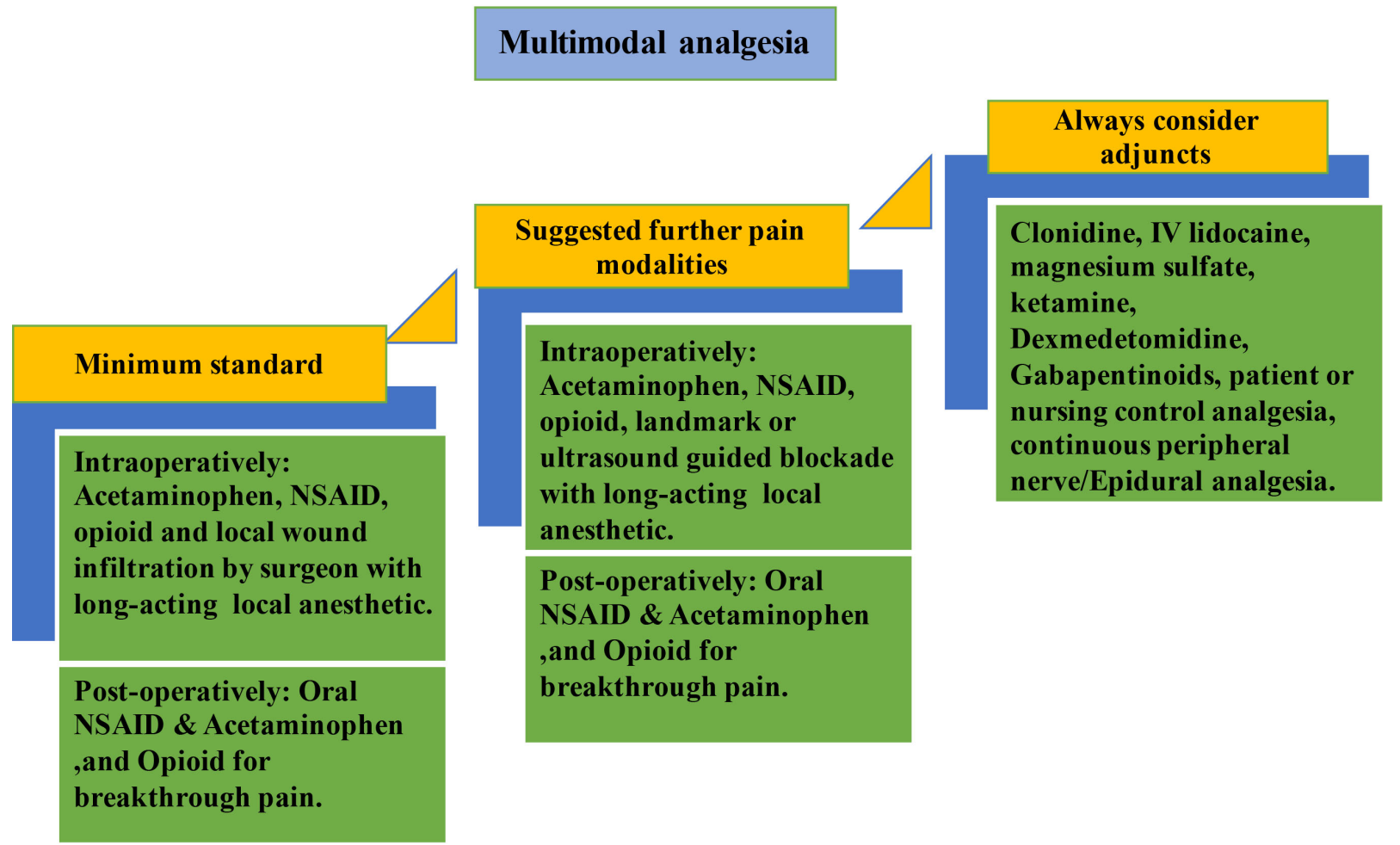

F I G U R E 2. Approach to perioperative pain management.

and $0.9 \%$ saline carries the risk of hyperchloremic metabolic acidosis [18, 19].

Children have the same fluid composition as adults, but a larger extracellular compartment (i.e., $40 \%$ in neonates comparted to $20 \%$ in adults) [19]. Therefore, in case of large amount fluid administered, the fluid osmolality and composition are pivotal in maintaining intravascular homeostasis [18, 19].

In presence of hemodynamic instability, boluses of 10$20 \mathrm{~mL} / \mathrm{kg}$ followed by vasoactive agent are usually recommended, although there is no unanimous agreement [21]. In the presence of hypovolemia poorly responsive to crystalloids, $5-10 \mathrm{~mL} / \mathrm{kg}$ of colloids (albumin, gelatins, hydroxyethyl starch - HES) may be considered. It must be taken into account, however, that colloids carry important side effects, such as anaphylactic reactions, kidney injury, coagulopathy and worsening of edema $[18,19]$. In neonatal intensive care, albumin failed to provide any advantage over crystalloids during fluid resuscitation [22], but it may preserve the glycocalyx better than semisynthetic colloids [23]. In Europe, HES solutions are contraindicated in critically ill patients [19]. Nevertheless, gelatine and third generation HES (HES 130) may be safely administered to children with normal renal function [19]. If colloids are employed, gelatins and HES may be used in balanced solutions to maintain the acid-base homeostasis [18].

\section{Normotension}

Variations of the blood pressure above and below the normal limits can determine organ hypoperfusion or hyperemia, particularly in the brain [24, 25]. In children, the safe blood pressure limits are still unknown [24, 25]. In general, hypotension is defined as blood pressure below the $5-10 \%$ percentile for age $[21,25]$. However, it is unknown whether critical organ 
perfusion is guaranteed at lower blood pressure levels under general anesthesia compared to awake conditions. A large cohort study showed that the lowest mean blood pressure in ASA 1 and 2 children under general anesthesia for non-cardiac surgeries was 17-22 mmHg lower than in awake children [26].

As a general rule, it is recommended that the mean arterial blood pressure should be kept above the infant's gestational age (in weeks) and never below $30 \mathrm{mmHg}$ [25]. Beyond this age and until 6 months, the mean blood pressure should be within $20 \%$ of the baseline and never below $45 \mathrm{mmHg}$ [21]. For older children, a mean blood pressure within $20 \%$ of the baseline and above $60 \mathrm{mmHg}$ may be acceptable [27]. Finally, the non-invasive blood pressure of the legs is often lower than the pressure in the arm. Alternative non-invasive hemodynamic monitors commonly underestimate the systolic blood pressure [28].

\section{Normal heart rate}

Neonates have a heart rate depended cardiac output. The maintenance of an appropriate age-based heart rate and contractility is pivotal to balance the maximum cardiac output and the myocardial oxygen consumption.

In children, the parasympathetic activity is impaired at birth, increases rapidly during the first year of life and then more slowly until late childhood [29].

During surgery, the autonomic system may be affected, and hypotension associated tachycardia may not always be present [30].

\section{Normoxemia}

Hypoxia is the most common intraoperative complication in children [31]. Nevertheless, oxygen saturation should be maintained $\leq 95 \%$ in preterm neonates, as hyperoxia is a wellknown risk for chronic lung disease, retinopathy of prematurity and brain injury [21]. In older children, an oxygen saturation above $95 \%$ is generally accepted [21]. It must be noted, however, that a large, single centre, retrospective study found that a high partial arterial oxygen concentration (partial arterial oxygen $>350 \mathrm{mmHg}$, or $>250 \mathrm{mmHg}$ in sicker children) at the time of the intensive care admission was an independent risk factor for increased mortality [32]. Until further studies clarify these findings, anesthesiologists may need to titrate the delivered amount of oxygen, as inadvertent intraoperative hyperoxia (partial arterial oxygen $>200 \mathrm{mmHg}$ ) is common [33].

\section{Normocapnia}

For every $\mathrm{mmHg}$ of partial arterial carbon dioxide $\left(\mathrm{CO}_{2}\right)$ change, there is directly proportional change in cerebral blood flow of approximately 3\% [4]. High partial arterial carbon dioxide increases cardiac index by $1-1.5 \%$ for every $\mathrm{mmHg}$, and shifts the hemoglobin dissociation to the right [34]. Moderate hypercapnia causes cerebral vasodilation and may lead to IVH and neurological injury [35], may increase the lower limit of cerebral blood flow autoregulation enhancing the detrimental effect of hypotensive episodes [4], and cause myocardial depression [36].

Severe, prolonged hypocapnia induces brain injuries such as cerebral ischemia, hemorrhage, periventricular leukomalacia [4]. Therefore, partial arterial carbon dioxide pressures should be maintained within normal limits [4, 27], and mild hypo or hypercapnia should be reserved to selected cases [27]. Finally, very low birth weight infants and those with severe lung disease may have inaccurate correlation between end-tidal $\mathrm{CO}_{2}$ and arterial $\mathrm{CO}_{2}$ with high difference as high as $20 \mathrm{mmHg}$ [4].

\section{Normonatremia}

For over half century, the ideal maintenance fluid has been considered mildly hypotonic [37]. In the last decades, however, it has become evident that up to $31 \%$ of postsurgical patients are hyponatremic, and surgery is independent risk factor for hospital-acquired hyponatremia [37]. On the contrary, perioperative hypernatremia is uncommon, although extreme premature neonates may be at risk of an excessive sodium load even with $0.2 \%$ sodium solutions [38].

Hyponatremia leads to encephalopathy, cerebral edema, and respiratory insufficiency, particularly in neonates [18]. On the contrary, isotonic fluids containing normal sodium concentration decrease the risk of perioperative hyponatremia [18]. Contrary to Ringer lactate and $0.9 \%$ saline, a balanced isotonic solution with $1 \%$ of glucose guarantees a sufficient provision of glucose, bicarbonate, chloride and a close to normal in-vivo osmolarity [19]. Balanced isotonic-glucose $1 \%$ solutions have demonstrated to reduce the risk of hyperchloremic metabolic acidosis comparing to $0.9 \%$ saline and are recommended for fluid resuscitation in Europe [18].

It must bear in mind that in infants $<32$ weeks, even mild hypernatremia $(<150 \mathrm{mmol} / \mathrm{L})$ can have neurodevelopmental sequalae [39].

\section{Normoglycemia}

After a transient decrease in the first few hours after birth, glucose stabilizes within normal range. However, neonates remain at high risk of hypoglycemia due to their metabolic rate, which is 2-3 times higher than adults [4].

Although transient mild to moderate hypoglycemia may not lead to neurocognitive injury, low plasma glucose concentrations are associated with neurological signs that range from irritability and poor feeding to seizures and ultimately death. Hypoglycemia may become particularly deleterious in the presence of hypotension [4].

Hyperglycemia is also an independent factor for prolonged length of stay and postoperative complications [40, 41]. Hyperglycemia $(>6.1 \mathrm{mmol} / \mathrm{L})$ and severe hyperglycemia $(>$ $11.1 \mathrm{mmol} / \mathrm{L}$ ) were reported in up to $93 \%$ and $27 \%$ of patients admitted to the pediatric intensive care unit (PICU) after major abdominal, thoracic [40] and cardiac [41] surgeries.

In order to maintain the intraoperative glucose levels within normal limit, a background infusion of $1-2.5 \%$ glucose at 10 $\mathrm{mL} / \mathrm{kg} / \mathrm{h}$ is recommended [18]. In healthy preschool children, $1 \%$ glucose appears to be sufficient to provide stable sodium and glucose level and avoid acid-base derangement, whereas 
patients with comorbidities (i.e., prematurity, parenteral nutrition, liver disease) will likely require higher concentrations [18]. Young age (particularly neonates), weight for age $<5^{\text {th }}$ percentile, ASA status $\geq$ III, the presence of gastric or jejunal tube, poor feeding, and abdominal surgery remain the most important risk factors for intraoperative hypoglycemia [42].

Given the lack of commercial, glucose-based balance solutions in North America, the American Academy of Pediatric recommends isotonic solution such as 5\% dextrose- $0.9 \%$ saline with $\mathrm{KCl}$ as fluid maintenance [43]. It must be noted, however, that in the presence of high perioperative levels of anti-diuretic hormone, hyponatremia can develop with 5\% dextrose- $0.9 \%$ saline infusion, once the glucose is reabsorbed and the excess of sodium is excreted [37].

\section{Normothermia}

Both perioperative hypo- and hyperthermia can be harmful in children and should be avoided [44, 45].

Normal body temperature is $36.0^{\circ} \mathrm{C}$ to $37.9^{\circ} \mathrm{C}$ rectally, 34.7 ${ }^{\circ} \mathrm{C}$ to $37.3^{\circ} \mathrm{C}$ axillary and $35.7{ }^{\circ} \mathrm{C}$ to $37.5^{\circ} \mathrm{C}$ tympanic [46]. Hypothermia is defined as a core body temperature $<36.5^{\circ} \mathrm{C}$, or a skin temperature $<36.0^{\circ} \mathrm{C}[45,47]$. Severe hypothermia occurs when the core and skin temperatures are $<32.0^{\circ} \mathrm{C}$ and $<31.5{ }^{\circ} \mathrm{C}[45,47]$, respectively.

In infants and neonates, unintentional hypothermia is common $(9-48 \%)$ [48, 49]. Passive and active warming techniques are effective in preventing hypothermia [45]. Common passive and active warming techniques used to maintain normal temperature perioperatively includes pre-warming of the operating room, forced-air warmer, fluid warmer, plastic cover, head cover, warming mattress, and airway heating and humidification [45, 50, 51]. For preterm neonates $<29$ weeks, radiant warmer, overhead heat lamps, vinyl bags, thermal mattresses, pre-warmed transport incubator and in particular polyethylene wraps have been demonstrated to be effective $[45,51]$. However, those interventions must be employed judiciously as they can also cause hyperthermia $\left(\mathrm{T}>37.5^{\circ} \mathrm{C}\right)$ $[45,48]$, as reported in $9 \%$ of neonates admitted to the intensive care unit after surgery [48].

Hypothermia is associated with multiple complications including respiratory distress syndrome, metabolic derangements, major brain injury, bronchopulmonary dysplasia, retinopathy of prematurity, necrotizing enterocolitis, coagulopathy, increased oxygen consumption, cardiac events, increase surgical wound infection, hospital length of stay [44, 45] and, in addition, altered drug pharmacokinetics and pharmacodynamics [44].

In infants, the thermoregulation mechanism is impaired particularly in the first 2 weeks of life [52]. The brown adipose tissue metabolism is the main route of heating until 6-12 months of age. Preterms $<30$ weeks of gestational age have no brown fat thermogenesis and remain at higher risk of hypothermia [53]. After induction, temperature drops dramatically in the first 10 minutes and continues for at least 60 minutes. Major risk factors are neonates, infants, low operating room temperature $\left(<23{ }^{\circ} \mathrm{C}\right)$ and major surgery [54]. The American Society of Anesthesiologists strongly recommends monitoring patient core temperature during cases of general anesthesia and neuraxial anesthesia lasting more than 30 minutes and to use of active and passive patient warming techniques to target a core temperature $36-37^{\circ} \mathrm{C}[55]$.

\section{No pain, no emergence delirium, no nausea and vomiting}

Pain associated with surgical stress delays postoperative ambulation and hospital discharge, promotes the development of chronic postoperative pain and increases morbidity and mortality [56]. Pain has been also associated with cognitive disturbances [57], increases cancer recurrence [58], impaired brain development [59] and immune system [60]. Despite the advancement in analgesics and pain control modalities, severe postoperative pain is present in up to $40 \%$ of patients [56]. Extensive pain management guidelines have been recently published by the pain committee of the European Society for Paediatric Anaesthesiology [61]. Multimodal or balanced analgesia is a strategy used to treat acute pain with several medications that target different receptors to reduce the risk of adverse effects associates to monotherapy, especially opioids [62]. The minimum multimodal analgesia [61, 62] (Fig. 2) should be achievable by all anesthesia providers even in institutions with limited resources and expertise. Neuraxial, regional analgesia, patient or nursing controlled analgesia are recommended when equipment, resources and expertise are available. Adjuvants should be considered whenever available.

Emergence Delirium (ED) is an anesthesia related complication and affects around $25 \%$ children undergoing surgery [63]. ED is associated with significant adverse events including injury to the patient and personnel, damage to incision sites, exacerbated parental anxiety, and increased nursing requirements, further resulting in an increased burden and cost to the healthcare system [64]. Once ED occurs, supplemental sedative and/or analgesic medications may be necessary, which delays patient discharge [65]. Children showing ED after anaesthesia are seven times more likely to have new-onset separation anxiety, apathy, eating and sleeping problems [66].

The risk postoperative nausea and vomiting (PONV) in children ranges from $9 \%$ to $70 \%$ and should be prevented, as part of the wide spreading ERAS recommendations [67]. Clear pediatric guidelines have been recently published [67] (Table 2).

Anti-emetic prophylaxis should be directed by patient's risk stratification for nausea and vomiting. It is recommended to use anti-emetic from different classes if rescue medications are needed postoperatively. Along with common medications such as dexamethasone and ondansetron, therapies such as liberal fluid administration $(30 \mathrm{~mL} / \mathrm{kg})$, lidocaine $(1.5 \mathrm{mg} / \mathrm{kg}$ followed by $2 \mathrm{mg} / \mathrm{kg} / \mathrm{h}$ ), or $\alpha_{2}$ agonists and non-pharmacological therapies (i.e., acupuncture) may also be considered [67].

\section{Conclusions}

Despite the advancements in drug safety and monitoring, pediatric anesthesia remains a specialty at high morbidity risk and low error tolerance.

Anesthesiologists who practice pediatric anesthesia should 
aim to maintain patient homeostasis at all time during the perioperative period.

The $10-\mathrm{N}$ principles provide clinical goals for a safe anesthesia conduct and should be integrated in pediatric training and daily practice.

\section{AUTHOR CONTRIBUTIONS}

IAA was responsible for manuscript preparation and reference selection. GB was responsible for literature review and manuscript editing.

\section{ACKNOWLEDGMENT}

We thank Dr. Engelhardt for the manuscript review before submission.

\section{CONFLICT OF INTEREST}

No conflict of interest to declare.

\section{REFERENCES}

[1] Weiss M, Vutskits L, Hansen TG, Engelhardt T. Safe anesthesia for every tot - the SAFETOTS initiative. Current Opinion in Anaesthesiology. 2015; 28: 302-307.

[2] Auroy Y, Ecoffey C, Messiah A, Rouvier B. Relationship between complications of pediatric anesthesia and volume of pediatric anesthetics. Anesthesia and Analgesia. 1997; 84: 234-235.

[3] Habre W, Disma N, Virag K, Becke K, Hansen TG, Jöhr M, et al. Incidence of severe critical events in paediatric anaesthesia (APRICOT): a prospective multicentre observational study in 261 hospitals in Europe. The Lancet Respiratory Medicine. 2017; 5: 412-425.

[4] McCann ME, Lee JK, Inder T. Beyond anesthesia toxicity. Anesthesia \& Analgesia. 2019; 129: 1354-1364.

[5] Weiss M, Bissonnette B, Engelhardt T, Soriano S. Anesthetists rather than anesthetics are the threat to baby brains. Pediatric Anesthesia. 2013; 23: 881-882.

[6] Kain ZN, Caldwell-Andrews AA. Preoperative psychological preparation of the child for surgery: an update. Anesthesiology Clinics of North America. 2005; 23: 597-614.

[7] Rosenbaum A, Kain ZN, Larsson P, Lönnqvist P, Wolf AR. The place of premedication in pediatric practice. Pediatric Anesthesia. 2009; 19: 817828.

[8] Davidson A, McKenzie I. Distress at induction: prevention and consequences. Current Opinion in Anaesthesiology. 2011; 24: 301-306.

[9] Manyande A, Cyna AM, Yip P, Chooi C, Middleton P. Nonpharmacological interventions for assisting the induction of anaesthesia in children. The Cochrane Database of Systematic Reviews. 2015; CD006447.

[10] Chow CHT, Van Lieshout RJ, Schmidt LA, Dobson KG, Buckley N. Systematic review: audiovisual interventions for reducing preoperative anxiety in children undergoing elective surgery. Journal of Pediatric Psychology. 2016; 41: 182-203.

[11] Evans C, Moonesinghe R. Virtual reality in pediatric anesthesia: a toy or a tool. Pediatric Anesthesia. 2020; 30: 386-387.

[12] Anderson BJ, Exarchos H, Lee K, Brown TC. Oral premedication in children: a comparison of chloral hydrate, diazepam, alprazolam, midazolam and placebo for day surgery. Anaesthesia and Intensive Care. 1990; 18: 185-193.

[13] Sury MRJ. Accidental awareness during anesthesia in children. Pediatric Anesthesia. 2016; 26: 468-474.

[14] Lopez U, Habre W, Van der Linden M, Iselin-Chaves IA. Intra-operative awareness in children and post-traumatic stress disorder. Anaesthesia. 2008; 63: 474-481.
[15] Beekoo D, Yuan K, Dai S, Chen L, Di M, Wang S, et al. Analyzing electroencephalography (EEG) waves provides a reliable tool to assess the depth of sevoflurane anesthesia in pediatric patients. Medical Science Monitor. 2019; 25: 4035-4040.

[16] Sury M. Brain monitoring in children. Anesthesiology Clinics. 2014; 32: 115-132.

[17] Fahy BG, Chau DF. The technology of processed electroencephalogram monitoring devices for assessment of depth of anesthesia. Anesthesia and Analgesia. 2018; 126: 111-117.

[18] Sümpelmann R, Becke K, Brenner S, Breschan C, Eich C, Höhne C, et al. Perioperative intravenous fluid therapy in children: guidelines from the Association of the Scientific Medical Societies in Germany. Paediatric Anaesthesia. 2017; 27: 10-18.

[19] Sümpelmann R, Becke K, Zander R, Witt L. Perioperative fluid management in children: can we sum it all up now? Current Opinion in Anaesthesiology. 2019; 32: 384-391.

${ }^{[20]}$ Frykholm P, Schindler E, Sümpelmann R, Walker R, Weiss M. Preoperative fasting in children: review of existing guidelines and recent developments. British Journal of Anaesthesia. 2018; 120: 469-474.

[21] Soriano SG, McCann ME. Is Anesthesia Bad for the Brain? Current knowledge on the impact of anesthetics on the developing brain. Anesthesiology Clinics. 2020; 38: 477-492.

[22] Shalish W, Olivier F, Aly H, Sant'Anna G. Uses and misuses of albumin during resuscitation and in the neonatal intensive care unit. Seminars in Fetal \& Neonatal Medicine. 2017; 22: 328-335.

[23] Milford EM, Reade MC. Resuscitation fluid choices to preserve the endothelial glycocalyx. Critical Care. 2019; 23: 77.

[24] Williams M, Lee JK. Intraoperative blood pressure and cerebral perfusion: strategies to clarify hemodynamic goals. Pediatric Anesthesia. 2014; 24: 657-667.

[25] McCann ME, Schouten ANJ. Beyond survival; influences of blood pressure, cerebral perfusion and anesthesia on neurodevelopment. Paediatric Anaesthesia. 2014; 24: 68-73.

[26] de Graaff JC, Pasma W, van Buuren S, Duijghuisen JJ, Nafiu OO, Kheterpal S, et al. Reference values for noninvasive blood pressure in children during anesthesia: a multicentered retrospective observational cohort study. Anesthesiology. 2016; 125: 904-913.

[27] Rhondali O, André C, Pouyau A, Mahr A, Juhel S, De Queiroz M, et al. Sevoflurane anesthesia and brain perfusion. Paediatric Anaesthesia. 2015; 25: $180-185$

[28] van Wijk JJ, Weber F, Stolker RJ, Staals LM. Current state of noninvasive, continuous monitoring modalities in pediatric anesthesiology. Current Opinion in Anaesthesiology. 2020; 33: 781-787.

[29] Eyre ELJ, Duncan MJ, Birch SL, Fisher JP. The influence of age and weight status on cardiac autonomic control in healthy children: a review. Autonomic Neuroscience: Basic \& Clinical. 2014; 186: 8-21.

${ }^{[30]}$ Stricker PA, Lin EE, Fiadjoe JE, Sussman EM, Jobes DR. Absence of tachycardia during hypotension in children undergoing craniofacial reconstruction surgery. Anesthesia and Analgesia. 2012; 115: 139-146.

[31] Murat I, Constant I, Maud'huy H. Perioperative anaesthetic morbidity in children: a database of 24,165 anaesthetics over a 30-month period. Paediatric Anaesthesia. 2004; 14: 158-166.

[32] Numa A, Aneja H, Awad J, Ravindranathan H, Singh P, Swil K, et al. Admission hyperoxia is a risk factor for mortality in pediatric intensive care. Pediatric Critical Care Medicine. 2018; 19: 699-704.

[33] Wakimoto M, Miller R, Chenault K, Tobias JD. Inadvertent hyperoxia during intraoperative care in neonates: a case-series study. Journal of Anesthesia. 2020; 34: 149-152.

[34] Akça O. Optimizing the intraoperative management of carbon dioxide concentration. Current Opinion in Anaesthesiology. 2006; 19: 19-25.

[35] Brown MK, Poeltler DM, Hassen KO, Lazarus DV, Brown VK, Stout $\mathrm{JJ}$, et al. Incidence of hypocapnia, hypercapnia, and acidosis and the associated risk of adverse events in preterm neonates. Respiratory Care. 2018; 63: 943-949.

[36] Zubrow AB, Hulman S, Kushner H, Falkner B. Determinants of blood pressure in infants admitted to neonatal intensive care units: a prospective multicenter study. Philadelphia Neonatal Blood Pressure Study Group. Journal of Perinatology. 1995; 15: 470-479.

[37] Oh GJ, Sutherland SM. Perioperative fluid management and postoperative hyponatremia in children. Pediatric Nephrology. 2016; 31: 53-60. 
[38] Baumgart S, Langman CB, Sosulski R, Fox WW, Polin RA. Fluid, electrolyte, and glucose maintenance in the very low birth weight infant. Clinical Pediatrics. 1982; 21: 199-206.

[39] Howell HB, Lin M, Zaccario M, Kazmi S, Sklamberg F, Santaniello N, et al. The impact of hypernatremia in preterm infants on neurodevelopmental outcome at 18 months of corrected age. American Journal of Perinatology. 2020.

[40] Wu Y, Lai W, Pei J, Zhao Y, Wang Q, Xiang B. Hyperglycemia and its association with clinical outcomes in postsurgical neonates and small infants in the intensive care unit. Journal of Pediatric Surgery. 2016; 51: 1142-1145.

[41] Moga M, Manlhiot C, Marwali EM, McCrindle BW, Van Arsdell GS, Schwartz SM. Hyperglycemia after pediatric cardiac surgery: impact of age and residual lesions. Critical Care Medicine. 2011; 39: 266-272.

[42] Riegger LQ, Leis AM, Golmirzaie KH, Malviya S. Risk factors for intraoperative hypoglycemia in children: a multicenter retrospective cohort study. Anesthesia \& Analgesia. 2021; 132: 1075-1083.

[43] Feld LG, Neuspiel DR, Foster BA, Leu MG, Garber MD, Austin K, et al. Clinical practice guideline: maintenance intravenous fluids in children. Pediatrics. 2018; 142: e20183083.

[44] Sessler DI. Complications and treatment of mild hypothermia. Anesthesiology. 2001; 95: 531-543.

[45] McCall EM, Alderdice F, Halliday HL, Vohra S, Johnston L. Interventions to prevent hypothermia at birth in preterm and/or low birth weight infants. Cochrane Database of Systematic Reviews. 2018; 2: CD004210.

[46] Oguz F, Yildiz I, Varkal MA, Hizli Z, Toprak S, Kaymakci K, et al. Axillary and tympanic temperature measurement in children and normal values for ages. Pediatric Emergency Care. 2018; 34: 169-173.

[47] Duryea EL, Nelson DB, Wyckoff MH, Grant EN, Tao W, Sadana N, et al. The impact of ambient operating room temperature on neonatal and maternal hypothermia and associated morbidities: a randomized controlled trial. American Journal of Obstetrics and Gynecology. 2016; 214: 505.e1-505.e7.

[48] Schroeck H, Lyden AK, Benedict WL, Ramachandran SK. Time trends and predictors of abnormal postoperative body temperature in infants transported to the intensive care unit. Anesthesiology Research and Practice. 2016; 2016: 7318137.

[49] Don Paul JM, Perkins EJ, Pereira-Fantini PM, Suka A, Farrell O, Gunn $\mathrm{JK}$, et al. Surgery and magnetic resonance imaging increase the risk of hypothermia in infants. Journal of Paediatrics and Child Health. 2018; 54: 426-431.

[50] Buisson P, Bach V, Elabbassi EB, Chardon K, Delanaud S, Canarelli J, et al. Assessment of the efficiency of warming devices during neonatal surgery. European Journal of Applied Physiology. 2004; 92: 694-697.

[51] Kim P, Taghon T, Fetzer M, Tobias JD. Perioperative hypothermia in the pediatric population: a quality improvement project. American Journal of Medical Quality. 2013; 28: 400-406.

[52] Harpin VA, Rutter N. Sweating in preterm babies. The Journal of Pediatrics. 1982; 100: 614-619.

[53] Asakura H. Fetal and neonatal thermoregulation. Journal of Nippon Medical School. 2004; 71: 360-370.
[54] Tander B, Baris S, Karakaya D, Ariturk E, Rizalar R, Bernay F. Risk factors influencing inadvertent hypothermia in infants and neonates during anesthesia. Paediatric Anaesthesia. 2005; 15: 574-579.

[55] Dobson G, Chow L, Flexman A, Hurdle H, Kurrek M, Laflamme C, et al. Guidelines to the practice of anesthesia - revised edition 2019. Canadian Journal of Anesthesia. 2019; 66: 75-108.

[56] Boselli E, Bouvet L, Bégou G, Dabouz R, Davidson J, Deloste J, et al. Prediction of immediate postoperative pain using the analgesia/nociception index: a prospective observational study. British Journal of Anaesthesia. 2014; 112: 715-721.

[57] Bushnell MC, Ceko M, Low LA. Cognitive and emotional control of pain and its disruption in chronic pain. Nature Reviews. Neuroscience. 2013; 14: $502-511$.

[58] Tavare AN, Perry NJS, Benzonana LL, Takata M, Ma D. Cancer recurrence after surgery: direct and indirect effects of anesthetic agents. International Journal of Cancer. 2012; 130: 1237-1250.

[59] Schneider J, Duerden EG, Guo T, Ng K, Hagmann P, Bickle Graz M, et al. Procedural pain and oral glucose in preterm neonates: brain development and sex-specific effects. Pain. 2018; 159: 515-525.

[60] Si H, Yang T, Zeng Y, Zhou Z, Pei F, Lu Y, et al. Correlations between inflammatory cytokines, muscle damage markers and acute postoperative pain following primary total knee arthroplasty. BMC Musculoskeletal Disorders. 2017; 18: 265.

[61] Vittinghoff M, Lönnqvist P, Mossetti V, Heschl S, Simic D, Colovic V, et al. Postoperative pain management in children: guidance from the pain committee of the European Society for Paediatric Anaesthesiology (ESPA Pain Management Ladder Initiative). Paediatric Anaesthesia. 2019; 28: 493-506.

[62] Sherman M, Sethi S, Hindle AK, Chanza T. Multimodal pain management in the perioperative setting. Open Journal of Anesthesiology. 2020; 10 : 47-71.

[63] Mason KP. Paediatric emergence delirium: a comprehensive review and interpretation of the literature. British Journal of Anaesthesia. 2017; 118: 335-343.

[64] Voepel-Lewis T, Malviya S, Tait AR. A prospective cohort study of emergence agitation in the pediatric postanesthesia care unit. Anesthesia and Analgesia. 2003; 96: 1625-1630.

[65] Vlajkovic GP, Sindjelic RP. Emergence delirium in children: many questions, few answers. Anesthesia and Analgesia. 2007; 104: 84-91.

[66] Kain ZN, Caldwell-Andrews AA, Maranets I, McClain B, Gaal D, Mayes LC, et al. Preoperative anxiety and emergence delirium and postoperative maladaptive behaviors. Anesthesia and Analgesia. 2004; 99: 1648-1654.

[67] Gan TJ, Belani KG, Bergese S, Chung F, Diemunsch P, Habib AS, et al. Fourth consensus guidelines for the management of postoperative nausea and vomiting. Anesthesia \& Analgesia. 2020; 131: 411-448.

How to cite this article: Is'haq Al Aamri, Gianluca Bertolizio. The importance of maintaining normal perioperative physiological parameters in children during anaesthesia. Signa Vitae. 2021;17(4):42-48. doi:10.22514/sv.2021.058. 